\title{
ANALISIS EFEKTIVITAS MESIN PADA DIVISI PENGALENGAN JAMUR DI PT XYZ MENGGUNAKAN METODE OVERALL EQUIPMENT EFFECTIVENESS
}

\author{
Aditya Haradito', Iman Sabarisman ${ }^{2}$ Satria Bhirawa Anoraga ${ }^{2}$ \\ ${ }^{1}$ Mahasiswa: DIII Agroindustri/Teknologi Hayati Veteriner/Sekolah Vokasi, UGM, Indonesia \\ Email: ${ }^{1}$ aditya.haradito@mail.ugm.ac.id \\ ${ }^{2}$ Staf Pengajar: DIII Agroindustri/Teknologi Hayati Veteriner/Sekolah Vokasi, UGM, Indonesia \\ Email: 2satriabhirawa@ugm.ac.id
}

\begin{abstract}
ABSTRAK
PT XYZ is one of the food canning companies in Indonesia. Nowadays, many companies are looking up for the alternatives to increase the company revenue by making a continous improvement in every process. This study has three aims to be achieved. First, knowing the value of availability rate, performance rate, and quality rate. Second, to determine the major cause which affecting the effectiveness value of the production machine. Third, to obtain the alternatives improvement to increase the machine effectivity. Overall Equipment Effectiveness (OEE) is a method to determine the effectiveness level of equipment utilization. The OEE method is known as one of the program applications of Total Productive Maintenance (TPM). This study measures the value of OEE in the production line of mushroom canning within two months. The values of this study are, availability rate is $89.99 \%$, performance rate is $65.13 \%$, and quality rate is $99.76 \%$. From those data, the obtained calculation value of OEE is $58.71 \%$, it shows that it has not reach yet the best practice (85\%) and need an improvement. The Losses in PT XYZ are breakdown losses, setup and adjustment losses, idle and minor stoppage losses, and defect losses. The alternatives improvement are tightening the maintenance schedule, as well as inspection before and after use on the machine. This maintenance is supported by a focus on the TPM pillar of self-improvement, which changes the workers' mindset, to change the mindset of the workers there should be an education and training to improve the ability of workers.
\end{abstract}

Keywords: overall equipment effectiveness (OEE)

\section{PENDAHULUAN}

PT XYZ adalah salah satu industri yang bergerak di pengalengan makanan, banyak produk yang telah dihasilkan dan dipasarkan hampir di seluruh wilayah Indonesia. Pemenuhan permintaan akan makanan kaleng menjadi tantangan yang harus dilewati, mesin yang digunakan juga harus bisa meningkatkan produktivitas. Kapasitas mesin dalam memproduksi bisa dilakukan analisis tingkat efektivitas dengan metode Overall Equipment Effectiveness (OEE). Era global seperti sekarang ini, perusahaan mulai banyak mencari alternatif untuk mengembangkan usaha perbaikan dalam meningkatkan revenue perusahaan, beberapa cara yang bisa digunakan yaitu dengan menambah kapasitas produksi, efesiensi terhadap kegiatan logistik, dan meningkatkan pelayanan kepada konsumen, dengan diimbangi 
melakukan perbaikan secara berkelanjutan terhadap setiap proses di perusahaan tersebut, hal tersebut diambil juga untuk tujuan dalam mengalokasikan dana perusahaan.

Salah satu metode pengukuran kinerja dan efektivitas mesin yang digunakan adalah Overall Equipment Effectiveness (OEE). Metode Overall Equipment Effectiveness (OEE) adalah metode pengukuran suatu tingkat efektivitas pemakaian suatu mesin atau peralatan pada perusahaan dengan menghitung ketersediaan mesin, performansi mesin, serta kualitas produk yang dihasilkan (Rahmadhani, 2014). Dalam dunia perawatan mesin, dikenal istilah Six Big Losses, ini adalah suatu hal yang harus dihindari oleh setiap perusahaan. Six Big Losses tersebut biasanya dikategorikan menjadi 3 kategori utama berdasarkan aspek kerugiannya, yaitu Downtime, Speed Losses dan Defects Losses yang dapat mengurangi efektifitas penggunaan mesin dalam kegiatan proses produksi. Untuk mengetahui dan meminimumkan losses yang terjadi, diperlukan adanya evaluasi kinerja dari mesin produksi. Dalam perhitungan, OEE mengukur efektifitas dengan menggunakan tiga sudut pandang untuk mengidentifikasi Six Big Losses (enam kerugian), yaitu availability, performance dan quality (Triwardani, 2013).

Berdasarkan penelitian yang dilakukan oleh Wahyuni (2015) tentang "Analisis Nilai Overall Equipment Effectiveness (OEE) Sebagai Dasar Untuk Perbaikan Efektivitas Kerja Mesin Cut Off Di Plant X PT ABC”, penelitian ini dilakukan pengukuran nilai OEE di salah satu lini produksi PT ABC pada periode tahun 2014. Nilai OEE yang diperoleh adalah 33.54\%, masih jauh di bawah nilai ideal OEE yaitu 85\%. Hasil penelitian menunjukkan, bahwa faktor utama yang menyebabkan rendahnya nilai OEE adalah nilai availability, dengan nilai $54.27 \%$. Setelah ditelusuri lebih lanjut, ditemukan bahwa yang menjadi penyebab utama adalah breakdown, yang mencapai 24.18\%. Dengan menggunakan metode FMECA (Failure Mode Effect and Critical Analysis) terhadap breakdown, ditemukan bahwa tingkat kekritisan paling tinggi terletak pada flexible coupling dan clamp, yang akar masalahnya disebabkan oleh unsur-unsur mesin, manusia, metode, material, dan lingkungan. Dalam mengatasi masalah tersebut, disarankan untuk menerapkan autonomous maintenance, salah satu pilar TPM. Penelitian yang dilakukan Wahyuni (2015) menjadi acuan dalam peneliti melakukan penelitian pada PT XYZ, apakah akar permasalahan dan saran perbaikan akan sama dengan yang dituliskan peneliti sebelumnya atau akan berbeda. Pada penelitian lain oleh Perdana (2017), nilai OEE pada PT Pagilaran masih dibawah nilai terbaik (85\%) hal ini disebabkan oleh breakdown losses, setup and adjustment losses, idle and minor stoppage losses, reduced 
speed losses. Usulan perbaikan yaitu dengan waktu loading mulai dari mesin, diperlukannnya perawatan yang lebih intensif, mulai dari pemeriksaan sebelum dan sesudah pemakaian.

Pentingnya nilai OEE dalam mengukur produktivitas mesin yang melatarbelakangi penelitian ini dengan tujuan untuk mengetahui nilai availability rate, performance rate, dan quality rate yang menjadi komponen nilai OEE pada divisi pengalengan jamur di PT XYZ. Setelah analisis nilai OEE, dilanjutkan dengan menghitung losses ada enam losses yang bias menjadi akar permasalahan. Setelah losses analisis dilanjutkan dengan menggunakan diagram pareto dan diagram sebab-akibat agar mengetahui akar permasalahan. Usulan perbaikan dari akar permasalahan yang didapat tersebut agar meningkatkan efektivitas mesin atau peralatan pada divisi pengalengan jamur di PT XYZ.

\section{METODE PENELITIAN}

Bahan-bahan yang digunakan dalam penelitian ini terdiri atas mesin yang berada pada divisi pengalengan jamur mulai dari mesin pencucian hingga mesin sterilisasi, yang diperlukan mulai data waktu mesin beroperasi (Hasil pencatatan dan pengamatan), waktu mesin yang terbuang (Hasil pengamatan), produk yang dihasilkan setiap mesin (Hasil Pencatatan dan hasil pengamatan), dan produk samping dari mesin (Hasil pencatatan dan taksiran) yang berada di divisi pengalengan jamur PT XYZ. Tahapan penelitian yang harus dilalui berawal dari melakukan uji kecukupan data, dimana uji kecukupan data ini dilakukan di setiap mesin yang diteliti, yaitu mesin pada divisi pengalengan jamur di PT XYZ. Data akan dikatakan cukup apabila nilai N' $<$ N sehingga tidak perlu adanya penambahan data dan dapat dilanjutkan dengan perhitungan OEE. Penggunaan tingkat kepercayaan antara 99, 95, dan 63 dengan nilai k masing-masing 3, 2, dan 1, sedangkan untuk nilai tingkat ketelitian bisa menggunakan nilai 1\%, 5\%, dan 32\% (Astuti, 2016). Uji kecukupan data pada penelitian ini menggunakan waktu bersih mesin beroperasi setiap harinya, di mana waktu tersebut diperoleh dari waktu kerja mesin dalam sehari dikurangi dengan keseluruhan waktu tunggu, kerusakan mesin, dan waktu penyetelan mesin. Setelah diketahui uji kecukupan data dan data dikatakan cukup maka analisis nilai dilanjutkan ke nilai OEE dan analisis losses. Penentuan dan analisis peta kendali $\mathrm{P}$ yang menggunakan ukuran cacat berupa proposi produk cacat dalam setiap sampel yang diambil (Roberts, 2005). Setelah peta kendali P jadi dilanjutkan analisis menggunakan diagram pareto dan diagram sebab-akibat untuk mendapatkan akar permasalahan dan dilanjutkan untuk mengambil usulan perbaikan untuk PT XYZ. 


\section{HASIL DAN PEMBAHASAN}

\section{Perhitungan Uji Kecukupan Data}

Sebelum melakukan pengukuran Overall Equipment Effectiveness, terlebih dahulu dilakukan uji kecukupan data. Penggunaan tingkat kepercayaan antara 99, 95, dan 63 dengan nilai $\mathrm{k}$ masing-masing 3, 2, dan 1, sedangkan untuk nilai tingkat ketelitian bisa menggunakan nilai $1 \%$, 5\%, dan 32\%. Penggunaan tingkat keyakinan dan tingkat ketelitian bias menyesuaikan karena keterbatasan waktu, tempat dan materi saat mendapatkan suatu data. Jumlah data yang digunakan pada uji kecukupan data adalah sebanyak 35 data. Berdasarkan hasil perhitungan uji kecukupan data, semua data cukup. Hal ini menandakan bahwa data yang akan digunakan pada perhitungan Overall Equipment Effectiveness dikatakan cukup. Penelitian ini menggunakan tingkat keyakinan $68 \%$ serta tingkat ketelitian $32 \%$ yang memiliki nilai k sebesar 1 dan nilai s sebesar 0,32. Perhitungan uji kecukupan data secara keseluruhan dapat dilihat pada Tabel 1.

Tabel 1. Perhitungan Uji Kecukupan Data

\begin{tabular}{|l|l|l|l|l|l|l|l|l|l|}
\hline \multicolumn{10}{|c|}{ Uji Kecukupan Data } \\
\hline Mesin & Washer & Blancher & Cooling & Grading & Sortasi & Slicing & Exhaust & Semmer & Retort \\
\hline N' & 1.42 & 1.31 & 1.20 & 1.39 & 1.39 & 4.05 & 2.58 & 3.02 & 1.79 \\
\hline N & 35 & 35 & 35 & 35 & 35 & 35 & 35 & 35 & 35 \\
\hline
\end{tabular}

\section{Analisis Availability Rate}

Availability Rate ini digunakan untuk mengetahui ketersediaan mesin beroperasi, dengan batas standar yang telah ditentukan yaitu 90\%, untuk mengetahui bahwa mesin tersebut sudah bekerja dengan efektif.

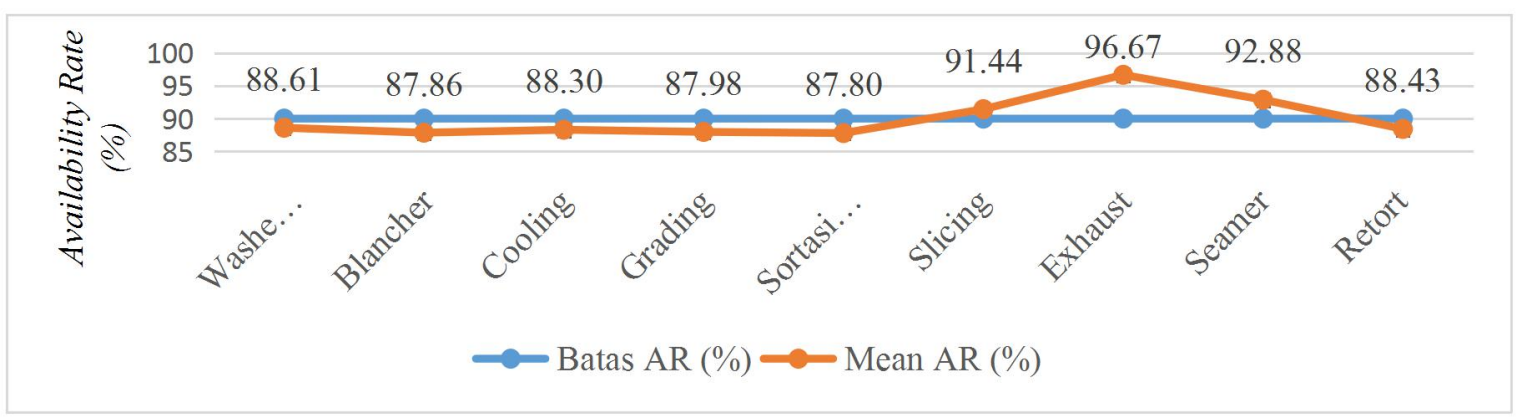

Gambar 1. Grafik Perbandingan Nilai Availability Rate

Gambar 1 menunjukkan nilai availability rate dari keseluruhan mesin pada divisi pengalengan jamur dibandingkan dengan nilai standar availability rate yaitu 90\%. Tiga mesin mempunyai nilai di atas batas minimum ketentuan, mesin itu adalah mesin slicing 
bernilai 91,44\%, mesin exhaust bernilai 96,67\%, dan mesin seamer bernilai 92,88\%. Mesin tersebut sudah berhasil mengoptimalkan penggunaan waktu operasi mesin, selain itu waktu penyetelan dan pengecekkan mesin hanya berkisar lima menit dan tidak ada waktu breakdown. Enam mesin yang mempunyai nilai availability rate dibawah nilai standard antara lain mesin washer tank bernilai 88,61\%, mesin blancher bernilai 87,86\%, mesin cooling bernilai $88,30 \%$, mesin grading bernilai $87,98 \%$, mesin sortasi belt bernilai $87,80 \%$, dan mesin retort bernilai $88,43 \%$. Mesin tersebut hanya perlu dilakukan perbaikan dalam peningkatan efektivitas. Waktu pembersihan yang lebih diefektifkan lagi, karena waktu pembersihan dan persiapan dari enam mesin bisa mencapai 30 menit, hal ini termasuk pengecekan, persiapan mesin, pengisian air ke dalam mesin, pembersihan sebelum proses produksi, dan pembersihan akhir proses produksi. Perbaikan yang bisa dilakukan terletak pada pemanfaatan waktu persiapan, pengecekan, dan pembersihan yang bisa dioptimalkan dengan cara pembersihan tidak perlu diulang-ulang apabila sudah mendetail sampai ke celah mesin dengan waktu 15 menit, pengecekan hingga waktu persiapan yang bisa dioptimalkan dengan lima menit saja yang dibutuhkan, dan mempertahankan agar mesin tidak ada kerusakan atau mesin berhenti mendadak saat bekerja, cara yang bisa dipakai untuk mempertahankan hal tersebut yaitu dengan pengecekan mesin sesuai jadwal, hal ini seperti pemberian pelumas dan pengencangan mur yang kendur agar pada saat penggunaan mesin tidak terjadi waktu breakdown. Karena breakdown bias menjadi salah satu losses.

\section{Analisis Performance Rate}

Analisis performance rate merupakan rasio kecepatan operasi aktual dari mesin dengan kecepatan ideal berdasarkan kapasitas produksi.

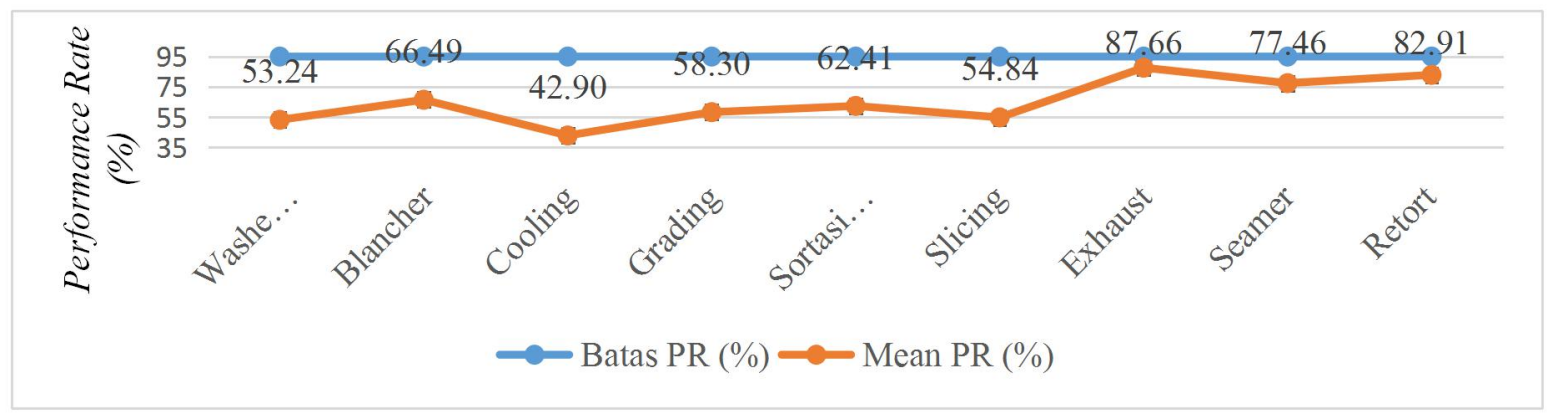

\section{Gambar 2. Grafik Perbandingan Nilai Performance Rate}

Berdasarkan Gambar 2, dapat diketahui bahwa nilai performance rate dari seluruh mesin yang berada pada divisi pengalengan jamur berada di bawah batas minimal yaitu 95\%. Perhitungan nilai performance rate mesin washer tank bernilai 53,24\%, mesin 
blancher bernilai $66,49 \%$, mesin cooling bernilai $42,90 \%$, mesin grading bernilai $58,30 \%$, mesin sortasi belt bernilai $62,41 \%$, mesin slicing bernilai 54,84\%, mesin exhaust bernilai $87,66 \%$, mesin seamer bernilai $77,46 \%$, dan mesin retort bernilai $82,91 \%$. Hal ini menunjukkan bahwa seluruh mesin pada divisi pengalengan jamur belum memberikan performa terbaik dalam menghasilkan produk, sehingga mesin tersebut belum memenuhi kriteria yang diharapkan. Nilai performance rate yang rendah pada mesin tersebut disebabkan oleh jumlah output yang dihasilkan lebih sedikit dibandingkan dengan jumlah output yang dihasilkan oleh mesin pada saat ideal cycle time mesin normalnya. Sebagai contoh, pada mesin washer tank pada tanggal 2 Juni 2017 dengan waktu produksi selama 2,8 jam, kapasitas $1.500 \mathrm{~kg}$ per jam, dan ideal cycle time 0,0006667 menit memiliki output $2339 \mathrm{~kg}$ yang lebih rendah dibandingkan dengan output yang seharusnya dihasilkan dengan waktu produksi tersebut, yaitu $4200 \mathrm{~kg}$. Realita yang ada ideal cycle time mesin belum dimanfaatkan secara maksimal, karena dari sisi panen jamur yang sedang mengalami grafik fluktuatif, hal itu terjadi agar perusahaan terus menghasilkan produk dalam memenuhi kebutuhan pasaran agar tetap bisa menjaga kepercayaan konsumen terhadap produk.

\section{Analisis Quality Rate}

Analisis quality ini dilihat dari banyaknya produk yang dihasilkan sudah memenuhi standar yang telah ditentukan atau tidak. Hal ini tentu dengan mempertimbangkan banyaknya defect dan pengulangan dari produk yang kurang sesuai.

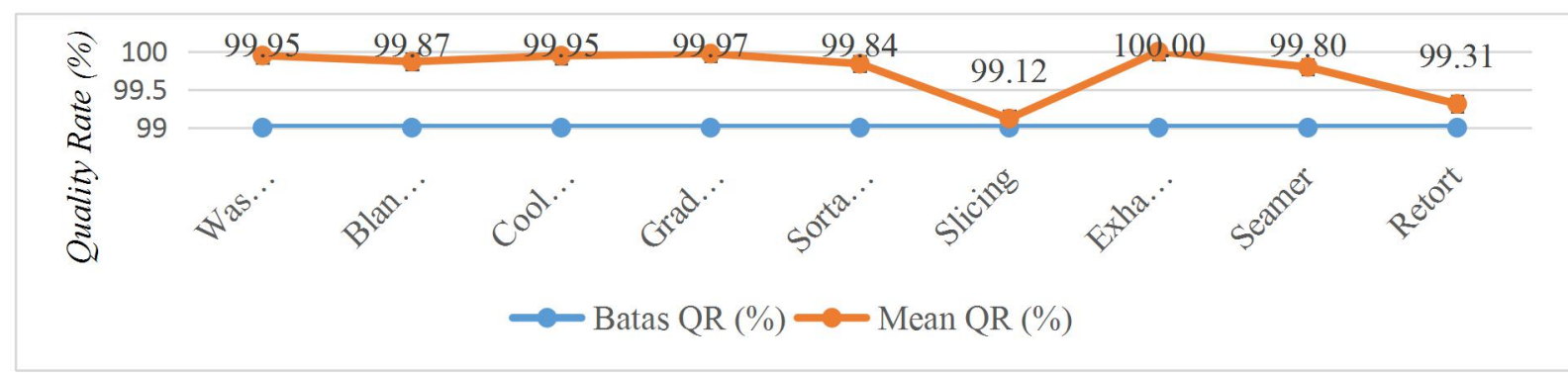

\section{Gambar 3. Grafik Perbandingan Nilai Quality Rate}

Dari Gambar 3 di atas menunjukkan nilai quality rate dari mesin pada divisi pengalengan jamur yang dibandingkan dengan nilai standar quality rate yaitu 99\%. Nilai quality rate dari seluruh mesin yang berada pada divisi pengalengan jamur berada di atas batas minimal yaitu 99\%. Perhitungan nilai quality rate mesin washer tank bernilai 99,95\%, mesin blancher bernilai 99,87\%, mesin cooling bernilai 99,95\%, mesin grading bernilai 99,97\%, mesin sortasi belt bernilai 99,84\%, mesin slicing bernilai 99,12\%, mesin exhaust bernilai $100,00 \%$, mesin seamer bernilai $99,80 \%$, dan mesin retort bernilai 
99,31\%. Mesin yang ada di perusahaan sudah bagus dalam menghasilkan keluaran dari masukan bahan, hanya sedikit produk yang terbuang dari total keluaran yang bersifat produk bagus.

\section{Analisis OEE}

Analisis overall equipment effectiveness (OEE) dilakukan untuk melihat tingkat efektivitas penggunan dari mesin pengalengan jamur periode bulan Juni 2017-Juli 2017.

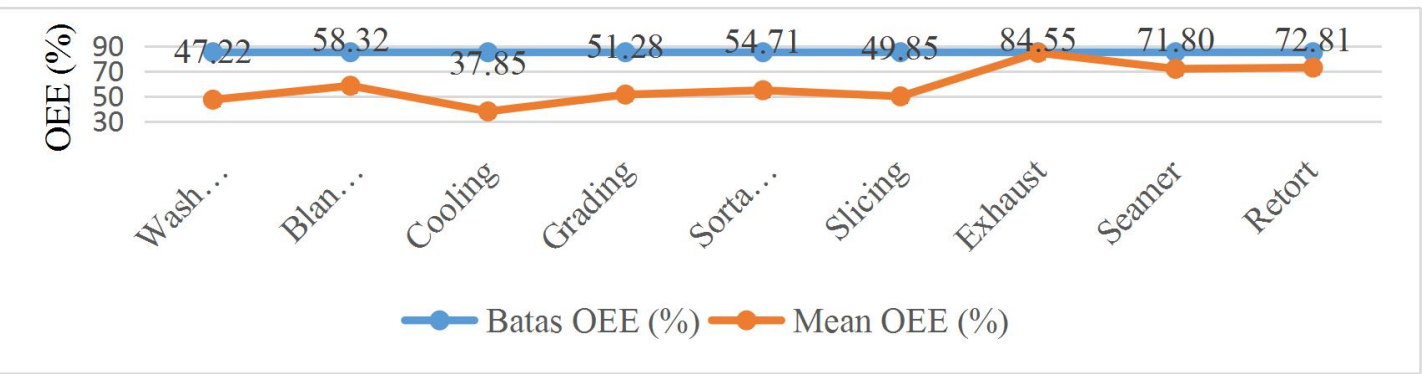

\section{Gambar 4. Grafik Perbandingan Nilai OEE}

Dari Gambar 4 di atas menunjukkan nilai OEE dari keseluruhan mesin pada divisi pengalengan jamur dibandingkan dengan nilai standar OEE yaitu 85\%. Mesin pada divisi pengalengan jamur seluruhnya mempunyai nilai OEE dibawah nilai standar, mesin washer tank dengan nilai 47,22\%, mesin blancher dengan nilai 58,32\%, mesin cooling dengan nilai 37,85\%, mesin grading dengan nilai 51,28\%, mesin sortasi belt dengan nilai $54,71 \%$, mesin slicing dengan nilai 49,85\%, mesin exhaust dengan nilai $84,55 \%$, mesin seamer dengan nilai $71,80 \%$ dan mesin retort dengan nilai $72,81 \%$. Hal ini menunjukkan bahwa hanya mesin exhaust yang sudah memiliki tingkat efektivitas yang baik. Rendahnya nilai OEE pada mesin washer tank, blancher, cooling, grading, sortasi belt, slicing, seamer dan retort disebabkan oleh pengaruh nilai performance rate yang berada di bawah batas minimum yang ditentukan, dan juga dari nilai availabillity rate enam mesin (washer tank, blancher, cooling, grading, sortasi belt, dan retort) yang juga masih berada di bawah batas minimum. Nilai OEE dipengaruhi oleh tiga faktor yaitu ketersediaan, kapasitas mesin, dan kualitas. Karena itu perlu perbaikan agar angka OEE bisa sesuai standar perusahaan tingkat dunia yaitu $85 \%$ dengan memperbaiki ketiga faktor yang mempengaruhi nilai OEE.

\section{Analisis Six Big Losses}

Analisis Six Big Losses (enam kehilangan) bertujuan agar perusahaan mengetahui apa saja dari keenam faktor yang mengakibatkan kehilangan-kehilangan dan mengetahui tingkat efektif dari mesin di line pengalengan jamur di PT XYZ yang menjadi prioritas 
pertama diperbaiki. Dari analisis OEE terlihat bahwa kinerja operasi pengalengan makanan pada PT XYZ masih perlu diperbaiki agar mencapai nilai maksimal. Adapun rata-rata kerugian (losses) dari bulan Juni 2017 sampai dengan bulan Juli 2017, seperti terlihat pada Tabel 2 .

\section{Tabel 2. Presentasi Nilai Kerugian (Losses)}

\begin{tabular}{|c|c|c|c|c|c|c|c|}
\hline \multirow{3}{*}{ No } & \multicolumn{2}{|c|}{ Downtime Loss (\%) } & \multicolumn{2}{c|}{ Speed Loss (\%) } & \multicolumn{2}{c|}{ Defect Loss (\%) } \\
\cline { 2 - 8 } & $\begin{array}{c}\text { Mesin } \\
\text { Losdown }\end{array}$ & $\begin{array}{c}\text { Setup \& } \\
\text { Adjustment } \\
\text { Losses }\end{array}$ & $\begin{array}{c}\text { Idle \& } \\
\text { Minor } \\
\text { Stoppages } \\
\text { Losses }\end{array}$ & $\begin{array}{c}\text { Reduced } \\
\text { Speed } \\
\text { Losses }\end{array}$ & $\begin{array}{c}\text { Rework } \\
\text { Losses }\end{array}$ & $\begin{array}{c}\text { Defect } \\
\text { Losses }\end{array}$ \\
\hline \multicolumn{2}{|c|}{ Rata-Rata } & 0,099271 & 9,29814 & 30,74813 & 0,00000 & 0,00000 & 0,13414 \\
\hline
\end{tabular}

Pada analisis losess terlihat bahwa rata-rata losses terbesar terdapat pada idle and minor stoppages losses yang mana rata-rata dari keseluruhan alat berkisar antar 30,748\%. Di posisi kedua disebabkan oleh Setup \& Adjustment Losses dengan rata-rata nilai 9,298\%. Ketiga ada Defect Losses sebesar 0,1341\% dan keempat ada Breakdown Losses dengan total $0,0993 \%$. Penjelasan di bawah ini akan membahas mengenai kehilangan (losses). Di bawah ini akan ditampilkan P-chart dari losses yang terdapat pada PT XYZ.

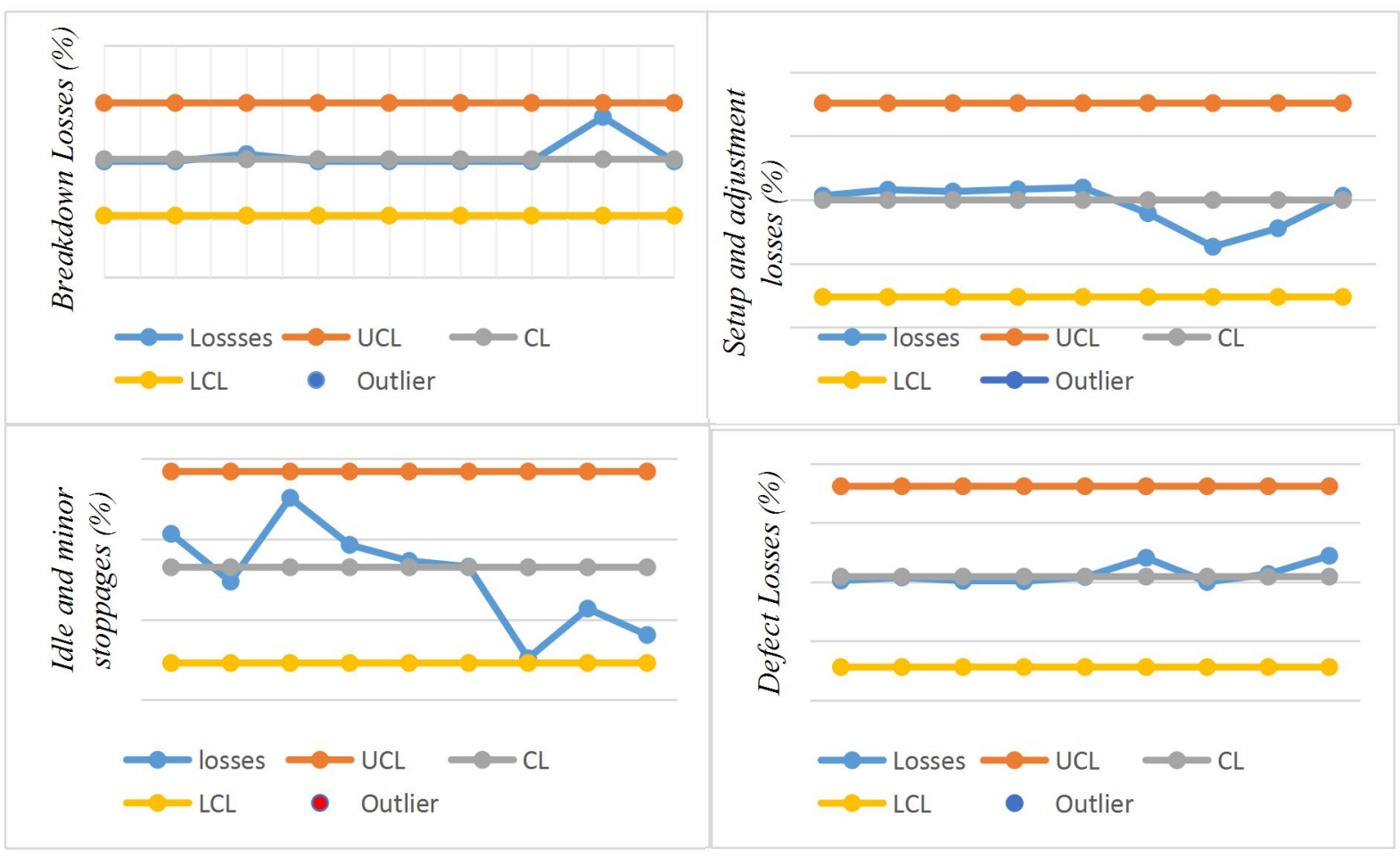

Gambar 5. P-Chart Losses

Pada Gambar 5 dapat diketahui grafik nilai kehilangan yang terserap dari keseluruhan mesin yang ada di PT XYZ. LCL yang bernilai di bawah 0 maka dianggap 0 dan data sudah seragam (Bakhtiar, 2013). Diketahui pada grafik p-chart di atas bahwa kehilangan 
(losses) dari keseluruhan mesin masih diantara batas kontrol. Batas atas, batas tengah dan batas bawah dari setiap losses berbeda, karena faktor angka yang menjadi dasar perhitungan berbeda. Sembilan titik pada peta kendali $\mathrm{P}$ menggambarkan rangkaian mesin yang ada di PT XYZ, berawal dari mesin pencuci, mesin pemasak atau pemanas, mesin pendingin, mesin grading, mesin sortasi, mesin pemotong jamur, mesin pemasukan jamur ke dalam kaleng, mesin penutup kaleng, dan mesin retort.

\section{Analisis Losses dengan Diagram Pareto}

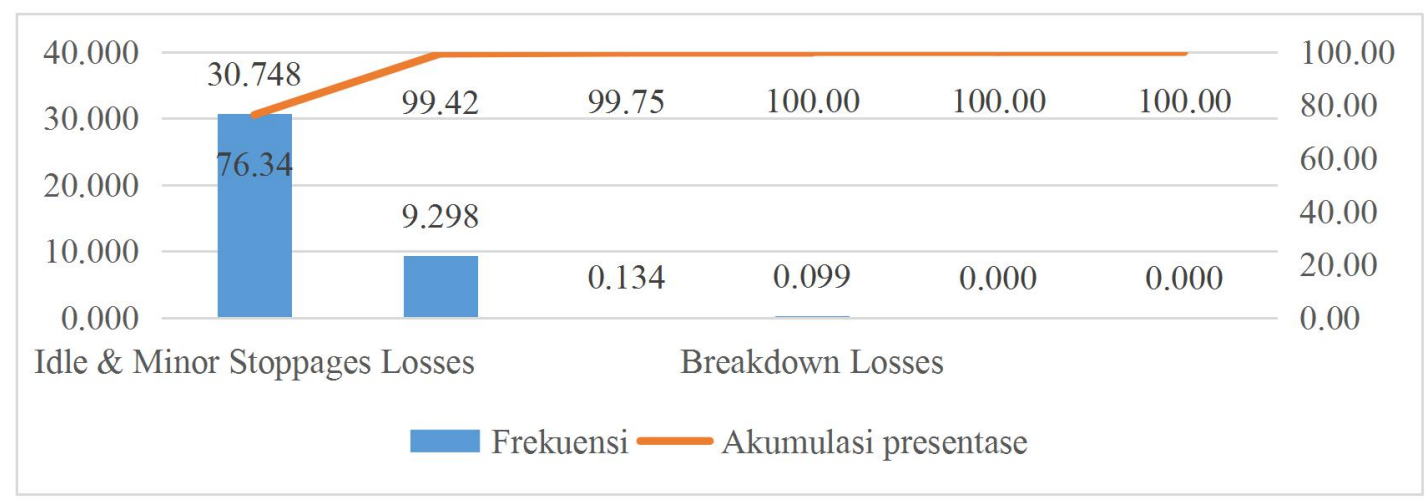

\section{Gambar 9. Diagram Pareto Analisis Losses}

Dapat dilihat di grafik bahwa nilai losses terbesar ada pada idle \& minor stoppages losses dan setup \& adjustment losses yang mewakili 76,34\% dan 23,08\% dari total losses perusahaan, hal ini tentu saja harus diperbaiki. Menarik sekali ketika mesin yang bisa menghasilkan produk harus kehilangan performa terbaiknya karena harus kehilangan waktu penyetelan dan mesin bekerja tanpa menghasilkan produk, maka dari itu efektivitas mesin perlu ditingkatkan dengan memaksimalkan waktu dan memaksimalkan kapasitas produksi mesin yang ada. Losses yang lainnya seperti breakdown losses berarti menandakan perlu adanya perbaikan pada penjadwalan pengecekkan dan perbaikan yang harus sesuai dengan jadwal yang telah ditentukan agar tidak ada kerusakan pada mesin. Defect losses terjadi ketika terdapat produk samping, kehilangan ini tak bisa dihilangkan tapi bisa diminimalisir dengan ketelitian dan kehati-hatian saat proses produksi berlangsung tiap harinya.

\section{Analisis Diagram Sebab Akibat}

Hasil dari diagram pareto menunjukkan ada dua penyebab paling besar dalam kehilangan yang diduga penyebab nilai efektivitas mesin pada divisi pengalengan jamur di PT XYZ di bawah nilai standar. Agar usulan perbaikan dari kehilangan dapat segera dilakukan, maka analisis terhadap faktor dari Six Big Losses yang mengakibatkan rendahnya efektivitas mesin dilakukan dengan menggunakan diagram sebab akibat atau 
biasa disebut dengan diagram ishikawa. Analisis ini dilakukan dengan pengamatan secara langsung ke lapangan dan melakukan wawancara terhadap karyawan atau operator yang terkait, yaitu operator bagian teknik, bagian quality control, dan juga bagian teknisi mesin. Untuk memperoleh hasil analisis yang sesuai diperlukan tools yang sesuai dengan data yang dikumpulkan, maka dibutuhkanlah diagram sebab akibat yang kemudian akan dirumuskan rencana perbaikan untuk megatasi akar permasalahan. Pada analisis sebab akibat dilakukan kepada kehilangan yang menempati urutan teratas menurut diagram pareto yaitu:

\section{a. Idle and Minor Stopages Losses}

Analisis masalah dengan metode sebab akibat, mengacu pada lima pokok parameter penyebab masalah, mulai dari manusia atau operator, mesin atau peralatan, lingkungan, metode, dan bahan bisa dilihat pada Tabel 3 dan pada diagram sebab akibat pada Gambar 10 .

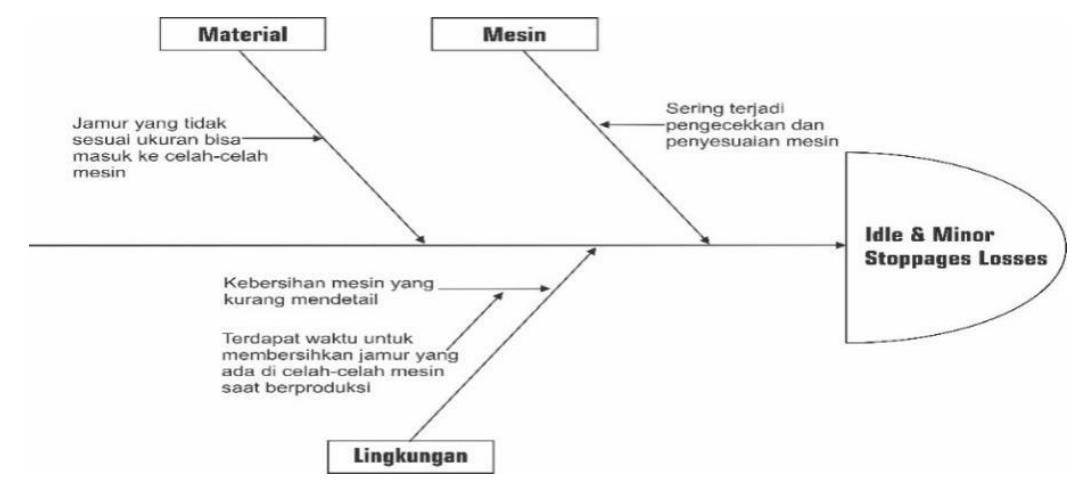

Gambar 10. Diagram Sebab Akibat Idle and Minor Stoppages Losses

\section{Tabel 3. Ulasan Penyelesaian Masalah Idle and Minor Stoppage Losses}

\begin{tabular}{|l|l|l|}
\hline No & \multicolumn{1}{|c|}{ Faktor-Faktor } & \multicolumn{1}{c|}{ Penyelesaian } \\
\hline 1 & $\begin{array}{l}\text { Mesin } \\
\text { Sering terjadi pengecekkan } \\
\text { pada waktu-waktu yang tidak } \\
\text { terjadwalkan }\end{array}$ & $\begin{array}{l}\text { a. Memanfaatkan jadwal pengecekkan yang sudah } \\
\text { ditentukan dengan teliti, agar tidak ada pengecekkan saat } \\
\text { mesin sudah beroperasi. }\end{array}$ \\
\hline 2 & $\begin{array}{l}\text { Lingkungan } \\
\text { Kebersihan mesin kurang } \\
\text { mendetail }\end{array}$ & $\begin{array}{l}\text { a. Pembersihan mesin dan areal sebelum dan sesudah } \\
\text { pemakaian sampai celah-celah sempit. }\end{array}$ \\
\hline 3 & $\begin{array}{l}\text { Bahan } \\
\text { a. Jamur yang masuk kecelah } \\
\text { mesin saat mesin menyala }\end{array}$ & $\begin{array}{l}\text { a. Perlu adanya pengaman di mesin agar jamur yang } \\
\text { ukuran kecil tidak masuk ke celah mesin }\end{array}$ \\
\hline
\end{tabular}

\section{b. Setup and Adjustment Losses}


Analisis masalah dengan metode sebab akibat, mengacu pada empat pokok parameter penyebab masalah, mulai dari manusia atau operator, mesin atau peralatan, lingkungan, bahan, dan metode bisa dilihat pada Tabel 4 dan pada diagram sebab akibat pada Gambar 11 berikut.

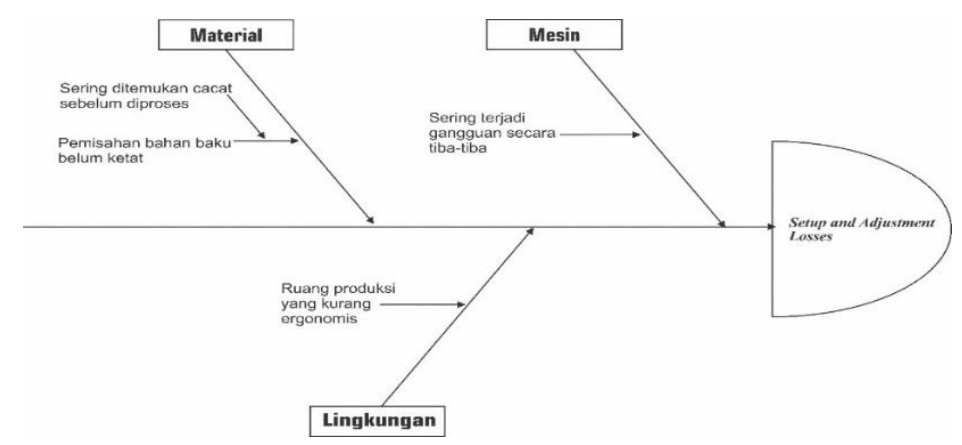

Gambar 11. Diagram Sebab Akibat Setup \& Adjustment Losses

Tabel 4. Ulasan Penyelesaian Masalah Setup and Adjustment Losses

\begin{tabular}{|c|c|c|}
\hline No & Faktor-Faktor & Penyelesaian \\
\hline 1 & $\begin{array}{l}\text { Mesin } \\
\text { a. Gangguan tiba-tiba pada mesin } \\
\text { atau peralatan }\end{array}$ & $\begin{array}{l}\text { a. Melakukan pengecekan secara berkala lebih dari } \\
\text { yang sudah dijadwalkan. }\end{array}$ \\
\hline 2 & $\begin{array}{l}\text { Lingkungan } \\
\text { a. Tempat kurang sesuai untuk } \\
\text { pekerja saat bekerja }\end{array}$ & $\begin{array}{l}\text { a. Penciptaan ruang yang ergonomis bagi pekerja } \\
\text { dapat meningkatkakan rasa nyaman saat bekerja. }\end{array}$ \\
\hline 3 & $\begin{array}{l}\text { Material } \\
\text { a. Jamur terkadang sulit } \\
\text { dipisahkan, dan kaleng ada } \\
\text { yang rusak sebelum diproses }\end{array}$ & $\begin{array}{l}\text { a. Pengecekan dan perencanaan penerimaan bahan } \\
\text { yang lebih ketat agar tidak terjadi kerugian saat } \\
\text { akan diproses }\end{array}$ \\
\hline
\end{tabular}

\section{Penerapan Total Productive Maintenance (TPM) Terkait Pilar TPM}

Penerapan total productive maintenance salah satunya terletak pada autonomous maintenace dan mengurangi cara breakdown maintenance yang melibatkan seluruh karyawan mulai dari pimpinan sampai dengan operator. Adanya kegiatan autonomous maintenance ini, setiap operator akan terlibat dalam perawatan dan penanganan setiap masalah yang terjadi pada mesin-mesin dibagian produksi. Terlihat PT XYZ menerapkan sistem pemeliharaan terencana, dimana penanganan kerusakan mesin yang terjadi disana merupakan tanggung jawab pada bagian maintenance atau bisa dibilang teknisi. Pemeliharaan mandiri dilakukan dengan tujuan mengubah pola pikir operator, yang berfikir mereka hanya menggunakan peralatan dan orang lain yang akan memperbaikinya dapat diubah. Dengan cara ini perawatan mesin dan peralatan diindustri dapat berjalan dengan baik dan kerusakan dapat dicegah. Hal tersebut juga memerlukan waktu untuk melatih dan membina operator untuk menanamkan kemampuan dan keahlian yang 
dibutuhkan untuk melaksanakan autonomous maintenance. Kegiatan-kegiatan pemeliharaan mandiri yang dapat dilakukan oleh operator sebagai peningkatan efektivitas mesin adalah sebagai berikut:

1. Menghilangkan sumber masalah, seperti potongan jamur yang menumpuk pada bagian dalam mesin yang menyebabkan kerusakan, yaitu dengan menemukan cara yang tepat untuk membersihkan bagian-bagian yang sulit dijangkau.

2. Melakukan penanganan sementara jika ada kerusakan yang terjadi, dan petugas teknisi belum kunjung datang, jadi kondisi mesin tidak menjadi terlalu parah, bisa dengan cara letakkan alat-alat yang digunakan untuk perbaikan didekat mesin.

3. Mendata menggunakan check sheet pemeriksaan yang telah disediakan oleh bagian teknisi, sehingga operator dapat dengan tanggap bila ada kerusakan, tahu dibagian mana, dan langsung melaporkan kebagian teknisi. Pencatatan keluaran, produk samping, dan waktu mulai hingga berakhir mesin juga dibutuhkan untuk menganalisis losses dan efektivitas mesin.

4. Pemeliharaan mandiri secara penuh (fully autonomous maintenance) yaitu pengembangan kebijakan perusahaan untuk meningkatkan kegiatan pengembangan secara teratur dan menyeluruh, sesuai jadwal dan instruksi yang berkaitan.

Analisis di PT XYZ, yang mempunyai masalah dominan kehilangan waktu loading di idle and minor stoppages losses dan Set Up and Adjustment Losses. Perbaikan menggunakan cara autonomous maintenance serta mengurangi perbaikan jenis breakdown maintenance dapat membantu membangkitkan kesadaran operator dalam penanganan mesin dan dilakukan pelatihan rutin kepada operator, hal ini dapat mengurangi efek buruk yang akan timbul di lain waktu.

\section{KESIMPULAN}

Capaian nilai OEE pada mesin divisi pengalengan jamur PT XYZ dilihat dari ketiga faktor yang mempengaruhi nilai OEE, rata-rata nilai quality rate yang didapat pada divisi pengalengan jamur sudah melampaui nilai standar. Namun, nilai rata-rata availability rate dan nilai rata-rata performance rate masih di bawah nilai standar. Faktor kehilangan yang menyebabkan nilai yang masih di bawah standar adalah Idle and Minor Stoppage Losses, Setup and Adjustment Losses, Defect Losses, dan Breakdown Losses. Usulan perbaikan dari akar masalah penyebab utama dari losses di PT XYZ. 


\section{DAFTAR PUSTAKA}

Astuti, Rahmaniyah Dwi dan Irwan Iftadi. (2016). Analisis Dan Perancangan Sistem Kerja. Yogyakarta: Deepublish.

Bakhtiar, S, Suharto Tahir dan Ria Asysyfa Hasni. (2013). Analisa Pengendalian Kualitas Dengan Menggunakan Metode Statistical Quality Control (SQC) (Studi kasus: pada UD. Mestika Tapaktuan). Malikussaleh Industrial Engineering Journal 2 (1).

Perdana, Yulian Galih. (2017). Analisis Peningkatan Efektivitas Mesin Pengolahan Teh Terhadap Manajemen Perawatan Dengan Metode Total Productive Maintenance (TPM) Pada PT Pagilaran. Jurusan Diploma III Agroindustri, Univeritas Gadjah Mada.

Rahmadhani, Delia Fitri., Harsono Taroepratjeka dan Lisye Fitria. (2014). Usulan Peningkatan Efektivitas Mesin Cetak Manual Menggunakan Metode Overall Equipment Effectiveness (OEE) (Studi Kasus Di Perusahaan Kerupuk TTN). Jurnal Online Institut Teknologi Nasional 2 (4).

Roberts, Lon. (2005). SPC for Right-BrainThinkers. USA: Quality Press.

Triwardani, Dinda Hesti, Arif Rahman, Ceria Farela Mada Tantrika. (2013). Analisis Overall Equipment Effectiveness (OEE) Dalam Meminimalisi Six Big Losses Pada Mesin Produksi Dual Filters Dd07 (Studi Kasus : Pt. Filtrona Indonesia, Surabaya, Jawa Timur). Jurusan Teknik Industri, Universitas Brawijaya.

Wahyuni, Mawaddatul Fitri. (2015). Analisis Nilai Overall Equipment Effectiveness (OEE) Sebagai Dasar Untuk Perbaikan Efektivitas Kerja Mesin Cut Off Di Plant X PT ABC. Jurnal Ilmiah Universitas Bakrie 3 (2). 